\title{
Technologizing the Transcendental, not Discarding it
}

\author{
Pieter Lemmens ${ }^{1}$
}

Accepted: 10 December 2020 / Published online: 3 April 2021

(c) The Author(s) 2021

\begin{abstract}
In this reply I further defend my claim that the transcendental should always remain a primary concern for philosophy of technology as a philosophical enterprise, contra the empirical turn's rejection of it. Yet, instead of emphasizing the non-technological conditions of technology, as 'classic' thinkers of technology such as Heidegger did, it should recognize technology itself as the transcendental operator par excellence. Starting from Heidegger's ontological understanding of transcendence I show that while technical artifacts may indeed always conform to a certain horizon of understanding, they also constitute this horizon in specific ways. Following Stiegler I show that concrete technologies (technology with a small ' $t$ ') are not just empirical effects of an overarching movement of transcendence (Technology with a capital ' $\mathrm{T}$ ') but are originally constitutive of it. In response to Romele's critique that the social, language, images, imaginaries, symbols, etc. are also transcendentals, I argue that all these phenomena are always already conditioned by technical milieus. As for Besmer's contention that I offer a reductive interpretation of postphenomenology's notion of multistability, I argue that there are decisive systemic and organological limits to multistability offered by technical artefacts and that all variation in use and implementation is always constrained by inherent technical tendencies and processes of concretization. Agreeing with Besmer that the transcendental and the empirical should be understood not oppositional but compositional I argue that technology may be that which constantly 'mediates' between the two.
\end{abstract}

Keywords Transcendental · Transcendence · Empirical turn · Postphenomenology · Heidegger $\cdot$ Stiegler

First of all, I would like to thank both Kirk Besmer and Alberto Romele for their thoughtful and useful comments on my article, which were very much appreciated. In what follows I will try to further clarify the core intention of that article by responding to the remarks they've put forward, Besmer being somewhat more critical than Romele, who is mostly in agreement with the views I present and starts off admitting this straightforwardly yet then

This reply refers to the comment available online at https://doi.org/10.1007/s10699-020-09757-y and https://doi.org/10.1007/s10699-020-09758-x.

Pieter Lemmens

p.lemmens@science.ru.nl

1 Institute for Science in Society, Radboud University Nijmegen, Nijmegen, The Netherlands 
goes on offering a very interesting 'complication' to it, i.e., the claim that technology is just one of many 'transcendentals' and should not be given primacy above others such as language, the social, the symbolic and the imagination, a position I shall try to complicate further. Besmer, who is a card-carrying postphenomenologist, contends with my allegedly reductive, 'empiricist' depiction of the notion of multistability, a key concept in the postphenomenological tradition, and basically argues for moving away from framing the current state and possible future destination of the philosophy of technology in terms of the exclusionary dichotomy of transcendental versus empirical.

The first thing to notice, therefore, is that both authors have responded not predominantly to the central concern of my article, namely a defense of the continued usefulness of the notion of 'Technology with a capital T' for thinking about technology today and in particular against the backdrop of the Anthropocene, but have instead chosen to focus on the issue of the transcendental versus the empirical in the philosophy of technology, which I discuss relatively briefly in the first part of the article. ${ }^{1}$ In my view, though, these issues are related and I hope this will become clear in what follows. But let me first take on the issue of the transcendental and why I think this should always remain a primary concern for the philosophy of technology as a philosophical enterprise, notwithstanding the empirical turn's popular dismissal of it.

Before doing so, however, I should first make clear what I understand by the transcendental in this context. Like Romele (Romele 2020), but also with Dominic Smith (Smith 2018) and my co-authors Jochem Zwier and Vincent Blok (Zwier et al. 2016), I am convinced that philosophy of technology cannot simply dismiss the issue of the transcendental versus the empirical and restrict itself to empirical analyses of concrete technical artefacts - in practice mostly the latest gadgets churned out by the tech industry or else what Smith has called “"zeitgeist-seizing” technologies' (Smith 2018, 31)—without questioning how these artefacts are embedded in a larger technical or techno-economic system (up to the planetary scale of what is called the 'technosphere' today) and conform as it were to a certain horizon of understanding yet also affect this horizon in specific ways.

While Smith develops a new approach to the transcendental that is meant to overcome all the traditional, supposedly 'reified', 'mystical' or 'otherworldy' notions of transcendence rightfully rejected by the empirical turn (so he argues) and yet is aimed to be as broad as possible-formally and minimally defined as any approach 'that enquires into a priori conditions for X' (ibid., 12) - I derive my 'sense of the transcendental' simply from Heidegger's groundbreaking understanding of transcendence as characterizing the fundamental structure of Dasein as a being that, 'apriorically', transcends beings toward their being and thereby understands these beings, i.e., is onto-logical in its very being (Heidegger 2001, 206-7), an understanding also adopted by Stiegler and many others. ${ }^{2}$ The issue of transcendence thus conceived is basically the issue of being, i.e., of Dasein's being-in-theworld as openness to beings. ${ }^{3}$ It refers to what or rather how we are, to our way of being, which is the basic structure behind what the philosophical tradition has called subjectivity, yet not in the sense of relating to objects but more fundamentally as transcending beings

\footnotetext{
1 I have addressed this in more detail in: Lemmens (2017).

2 Cf.'The fundamental essence of the being-structure of the being that we are ourselves, is the transcendence of beings' (Heidegger 2001, 207).

3 Cf. Heidegger's remark in Being and Time that 'Being is the transcendens pure and simple' (Heidegger 1996, 33-4).
} 
toward their being, which makes any relating to objects-or 'epistemological transcendence'-first of all possible (Heidegger 1984, 165).

'The transcendental' then pertains to 'knowledge' about this dynamic structure of transcendence, which is not a 'knowledge' about innerworldly objects or entities and neither about some 'otherworldy' or 'noumenal' realm of ideal beings but, indeed, about being, which is never $a$ being. It is not ontic but ontological 'knowledge' or 'knowledge' about what Heidegger called the ontological difference, which Dasein as a transcending being permanently 'enacts' or 'executes' [Vollziehen] or rather, as the later Heidegger realizes, which 'pervades' Dasein and first of all allows it to transcend beings and thus constitutes its condition of possibility, i.e., grants it the ability of transcending (Heidegger 1991, 184). And philosophy is, and has always been, the enquiry into this condition. As Dominique Janicaud recalls, 'of all the disciplines of knowledge, it [i.e., philosophy; P.L.] is the only one taking as its essential topic the transcendence that inheres in, animates, and tears through being human' (Janicaud \& Mattéi 1995, 1).

And it does so, as Heidegger remarked, through explicit engagement with this transcendence, and that is to say by emphatically transcending (Heidegger 1996, 216). And this is what phenomenology in Heidegger's view as ontological investigation is all about. Indeed as a transcendental discipline in this sense it is an aprioristic enquiry, investigating as it does into the understanding of being pre-ceding or coming before (Heidegger 1991, 163) and in that sense sur-passing or lying over beyond [meta in Greek] any understanding of beings, 'performed' as transcendence (ibid., 164). Traditionally the surpassing or 'overlying' character of this understanding was called meta-physical: surpassing the understanding of (the) beings (of nature) (ibid.). Hence the usual conflation of transcendental and metaphysical.

It is my contention that philosophy of technology, or in any case continental philosophy of technology (to which Smith explicitly subscribes as well) should inquire into the role of technology - both with a small ' $t$ ' and a capital ' $T$ ' as I will show-in the dynamic of transcendence in the sense briefly sketched above. This indeed means that it should understand itself primarily, though not exclusively, as a transcendental discipline. This is not to say, therefore, that it should retract from empirical engagement with technology and refrain from dealing with concrete technical artefacts altogether. On the contrary, as philosophy of technology it should focus its attention on technologies as a matter of course. Yet these should be analyzed in relation to the dynamic of transcendence that inheres in our beinghuman as being-in-the-world, both individually and collectively. Whether one refers to this dynamic with another term such as 'subjectivation' (with Foucault or Agamben) or 'individuation' (with Simondon, Deleuze and Stiegler) is of secondary importance.

We know or at least should know how Heidegger himself thought about this relation. Briefly put: it is the dynamic of transcendence that for Heidegger pre-constitutes all development and use of concrete technical artefacts. It is important to realize that this dynamic is theorized throughout Heidegger's career in an increasingly 'de-subjectivized' or 'dehumanized' way. We should indeed admit that Heidegger, as a phenomenologist, is a transcendentalist thinker, but how he thinks transcendence and how he conceives of what are called the transcendental conditions of possibility for (technical) objects or beings to appear, fundamentally changes in the course of his 'thinking path'. As Reiner Schürmann has shown in great detail, one can distinguish three phases in the way Heidegger conceives of the transcendental, whereby the human as initial locus of origination is increasingly decentralized. First, in Being and Time, the transcendental subject of Kant and Husserl is replaced by Dasein's existential-ontological structure of care. Then, in the onto-historical phase, Dasein makes place for an always historically situated 'humanity' [Menschentum] 
responding to a particular, epochal modality of unconcealment or what Schürmann calls an 'economy of presence'. And finally, in the latest texts on Enframing and the fourfold, 'humanity' is succeeded by what he calls 'thinking', understood as correspondence to the extra-epochal 'event of appropriation' [Ereignis] (Schürmann 1990, 63-77). In this development, the transcendental is not only de-humanized but also thoroughly historicized. It loses its foundation in subjectivity and is 'returned' to being itself, understood first as epochal history and then as (post-epochal or post-metaphysical) event of appropriation.

While the early Heidegger conceives of technical artefacts, or beings ready-to-hand, as constituted by the 'projective-thrown' structure of Dasein, and the middle Heidegger understands them as flowing from being as machination [Machenschaft] which also 'stamps' Dasein as subjectivity, the late Heidegger develops his most widely known thesis that all use and fabrication of technical artefacts and machines in modernity proceeds from-or is conditioned by - a mode of understanding and revealing of beings that he calls Enframing [Gestell] (Heidegger 1977, 12, 19). Enframing is explicitly understood as a claim or imperative to which modern humans as productive and manufacturing beings only respond, and it is in this imperative, as it were, that the 'transcendental conditions of possibility' for all concrete technologies and technological innovation for Heidegger reside. They are thoroughly historical, epochal and resolutely non-ontic. They also condition human technical ingenuity and intelligence. And they ultimately unfold from their inception in the ancient Greek understanding of being as physis interpreted as constant presence [ousia]. It is this metaphysical understanding of being, oblivious of being as being, which has destined the history of West toward the technological exploitation of nature. Modern technology is the culmination of this metaphysical destiny that started with the Greek inception and still rules over our existence, although the growing danger [Gefahr] of its absolute reign can also make us aware of our wholesale implication in this destiny, possibly re-opening us toward our ontological freedom, which technology as this destiny is ever more insistently laying claim upon.

Technology in this transcendental, metaphysical or 'essential' (understood as destinal) sense-Gestell or Geschick as Heidegger's 'Technology with a capital T' - has nothing to do with concrete technologies for Heidegger. It is nothing technological itself yet overdetermines all technological action and conditions all concrete technological invention. The latter, and this is what I want to emphasize here, never conditions for Heidegger that technological revealing that is Enframing itself. As he writes in his essay on 'The Question Concerning Technology': 'all those things that are so familiar to us and are standard parts of an assembly, such as rods, pistons, and chassis, belong to the technological. The assembly itself, however, together with the aforementioned stock parts, falls within the sphere of technological activity; and this activity always merely responds to the challenge of Enframing, but it never comprises Enframing itself or brings it about' (ibid., 20-21; my emphases). This is to say that 'technology with a small t', i.e., concrete technical artefacts and larger technical assemblies, never affect or retro-act upon 'Technology with a capital T' or the essence of technology, which for Heidegger is nothing other than being itself in its ever more withdrawing nature, increasingly closing off Dasein's original openness to being or ontological freedom. ${ }^{4}$

The latter, and this is crucial, becomes ever more 'enframed', determined and thereby 'enclosed' the more technology ('with a small t') evolves and gets implemented in daily

\footnotetext{
4 'Technology with a capital T' sensu Heidegger ultimately boils down to persistence in the oblivion of being as Dasein's in-sistent response to the withdrawal of being, i.e., metaphysics.
} 
life, yet the fundamental enclosure-the real 'danger'-always remains ontological for Heidegger and not technological. It involves our ongoing 'transcendental' implication in 'Technology with a capital T', not the empirical avalanche of technical objects and systems (for instance through the Internet and social media, which are only 'consequences' of our increasing implication in Enframing).

For Stiegler, to whom I will now turn, this diagnosis attests to Heidegger's oblivion or forgetfulness of technology, and that is to say of 'technology with a small t', in the sense of its constitutive and conditional nature with respect to the dynamic of transcendence that inheres in human Dasein, a critique Stiegler brings up against Heidegger. Far from being only empirical effects or outcomes of a movement of transcendence that is forgetful of its ground in an original openness to being, concrete technologies for Stiegler are precisely constitutive, i.e., originally constitutive for this movement of transcendence. They first of all open up or enable the openness to being —or what Heidegger called Dasein —within the human being. While Heidegger imagines the openness to being of Dasein as a 'gift' of being as it were- 'a pure feat of being that "maintains" man in the open', as Michel Haar puts it, rightly arguing that everything distinctively 'human' (understood as Dasein) for Heidegger derives originally from being (Haar 1993, 61)—Stiegler instead claims that the human openness to being is originally technically constituted.

Although it is impossible to briefly recall the extensive phenomenological explication here (see my article in this issue but also Lemmens 2017), Stiegler shows that 'technology with a small t' lies at the very origin of the ontological openness or freedom of Dasein, or in other words of the dynamic of transcendence. Human transcendence and existence are characterized by an 'originary technicity' (Stiegler 1998, 4), an original conditioning by technical artefacts (initially stone tools, which already opened up a kind of world or ontological horizon for the first hominids, however 'primitive'), but more fundamentally by an original lack or de-fault of origin, for which 'technology with a small t' as it were originally and continuously 'compensates' (ibid., 17). Technology, thus, must be understood as the 'empirical transcendental', as the 'original'-though in the sense of an 'aposterioric a priori' and thoroughly accidental-condition of possibility of any form of human transcendence. As such, transcendence is technologized.

It is indeed true, as Romele shows at great length, that postphenomenology considers technical artefacts in some sense transcendentally when it analyzes how they condition specific relationships to the world within human-technology-world relations such as embodiment, hermeneutic, alterity, background, cyborg and composite relations. ${ }^{5}$ And indeed it has adopted ANT's (Actor-Network-Theory) account of how networks of technical objects and/or 'actants' condition human behavior (and vice versa), and sure, it makes some room for transcendental considerations in the context of its so-called 'ethical turn'.

In all this, however, and apart from the fact that the transcendental role of technology is never explicitly theorized phenomenologically but only demonstrated empirically in postphenomenology, what I would like to point out here is that postphenomenologists never seem, or want, to realize how the acknowledgement of technology's transcendental status allows us, and indeed compels us, to completely rethink, beyond Heidegger and

\footnotetext{
5 Only think of Ihde's fine analyses of the decisive role of the telescope, neglected by Husserl, in the paradigm switch accomplished by Galileo and others (Ihde 1990, 54-8) and his later forays into how writing technology has conditioned science and thought more generally, something only glimpsed by Husserl in his later writings on the origin of geometry (Ihde 2016, 24, 100), a fact also noted by Derrida and Stiegler (Stiegler 1998).
} 
all metaphysics, the fundamental phenomenon of transcendence as such which, if we follow Heidegger, has occupied philosophy from its very beginning until today and has been the very 'thing' - a thing that is no-thing - that has as it were animated its questioning throughout all of its history without ever being questioned itself. For Heidegger this was the history of being but it can now be reinterpreted, with Stiegler, as the history of technological mutations or exteriorizations periodically putting humans into question as well as their collective responses to it or interiorizations of it-manifesting in successive interpretations of being. Transcendence-as well as ex-istence-should be rethought as a phenomenon that is first of all opened up by a dynamic of technical ex-teriorization and can only be conceived of as fundamentally supported by technical artefacts. The epochality of Heidegger's history of being as the trajectory of successive figures of transcendence should then be reinterpreted as rooted in successive phases or epochès of technology in the sense of technological interruptions or suspensions (epochè means to interrupt or suspend) of former technical systems by new ones and their subsequent adoption by humans so as to constitute an epoch of being sensu Heidegger (or an 'economy of presence' sensu Schürmann, which is also similar to an episteme sensu Foucault or, within a completely different register, a 'logic of appearance' sensu Badiou). ${ }^{6}$

The withdrawing claim of being can then be understood in terms of what Stiegler calls the 'doubly epochal redoubling' dynamic, which consists of a twofold movement, the first epochè being that of the process of technical becoming [devenir] or exteriorization periodically installing a new technical system that interrupts or disrupts the older (i.e., passing) system, the second epochè being the adoption of the new technical system by the social and other systems, transforming this process of becoming into individual and collective projects of existence, i.e., of an existential future [avenir] (cf. Stiegler 2011, 7). All transcendence as understanding of and relating to beings, all 'noetic life', all noesis, is conditioned by technological mutations or disruptions, such as the digital disruption of today, which completely reconfigures the conditions of what Hannah Arendt called the 'life of the mind' and most generally of what Stiegler calls individuation.

As already indicated, Romele contends that technology is not the only and not even the primary transcendental. Referring to the expression 'the transcendental of technology' in both a subjective genitive (technology as the transcendental condition) and an objective genitive sense (the transcendental condition of technology), he argues against the 'absolutization' of technology as the transcendental, conditioning everything that is human, and for the acknowledgement of a multiplicity of other, non-technological transcendentals that are themselves conditional for technology. As for the latter he lists language, images and imaginaries, but also nature and society, which should all be studied empirically and not postulated as ideal structures. As an example he refers to his own recent work on symbolic forms, derived from the sociology of Pierre Bourdieu, which may be considered as empirical transcendentals embodying a certain social logic biasing technological innovation in structural ways.

It is indeed the case, and also frequently noticed, that Stiegler's thesis of the human condition as a technical condition tout court and of human evolution as boiling down to techno-evolution smacks of technological reductionism, essentialism and determinism (cf.

\footnotetext{
${ }^{6}$ It may indeed be the case, as Romele suggests, that postphenomenology fails to grasp this because of its exclusive focus on the micro-perspective, but it should be added that postphenomenology, and most vehemently through the voice of its founding father, rejects any consideration of the transcendental altogether, also in the context of its 'cultural hermeneutics'.
} 
Vaccari 2009), to the point even of representing a 'theology of technics' (Mules 2009). I tend to agree with this, yet while Stiegler's understanding of technical conditioning is certainly not a variety of technological determinism since conditioning is not the same as determining - evolutionary, historical and societal change depends on how the process of technical exteriorization and conditioning (driven by what Leroi-Gourhan called the technical tendency) is each time collectively adopted and negotiated ${ }^{7}$ - technology remains for him the principal 'transcendental', i.e., the originary condition of possibility of the appearance and the continuation of 'the human' understood with Heidegger as Dasein or as the movement of transcendence described earlier, the 'enactment' of the ontological difference or the playing out of what Derrida called differrance. ${ }^{8}$

And I think Stiegler has good reasons for this. 'The human' in this sense has been able to come into being only as a result of a process of techno-logical exteriorization, of a cooriginal exteriorization of experience via technai (technical artefacts) and logoi (words, i.e., language). The very possibility of ex-isting outside of oneself and trans-cending beings toward their being - their meaning or sense-depends on ex-pression and the sharing of it through the ex-teriorized artefact. It is possible only as or in 'a life that places itself outside of itself by projecting itself in its technai, and which, in this way, ex-ists' (Stiegler 2015, 32). Also, the transgenerational continuation of Dasein as a mortal, finite mode of beingin-the-world depends on an inheritance process based on technical artefacts; no existential or cultural transmission is possible without extra-biological, ex-organic, i.e., technical vectors of transmission.

As for Romele's contention that the social, language, images, imaginaries and the symbolic in general are also transcendentals, my only response is that all these phenomena are always already and that is to say originally supported by a technical milieu that continually changes their parameters, and that is why, for instance, the current installment of the digital milieu completely overhauls the symbolic milieus, threatening them under current hypercapitalist conditions with 'desymbolization' (Stiegler 2013, 68ff) or even 'diabolization' (Stiegler 2015, 28). ${ }^{9}$ In that respect, I totally support Romele's timely plea for a 'political turn' in the philosophy of technology, so as to break with its 'industrially embedded', sadly conformist 'ethical turn' and recapture it as a politically astute, critical and self-critical discipline liberated from its servile co-optation by the tech industry.

Let me now turn to Besmer's comments on my interpretation of the notion of multistability and appreciation of the 'transcendental-empirical debate' in philosophy of technology. What should be clear by now is that intentionality, as embedded in transcendence, is not only 'often complicated by actual technologies' and mediated by them in 'multiple

\footnotetext{
7 Cf. 'the conditions in which tertiary retentions [or technical artefacts; P.L.] are set to work themselves depend on social organization. Clearly, these are conditioned by retentional organs, but these conditions are not determinations' (Stiegler 2015, 113).

8 Stiegler's view on technology is organological, meaning that the social organs (organizations) and the psychic organs (humans) are indeed always constituted by the technical organs but the latter are always differentially adopted by the former two in more or less emancipatory and autonomizing ways.

9 Andres Vaccari alludes to the work of the American psycho-linguist Michael Tomasello in arguing that it is not technics but sociality that is the crucial factor in the process of hominization and thus that 'sociality exceeds technics' (Vaccari 2009, 8). Although I cannot go into this argument here, it seems implausible to assume that this exceptional sociality and the 'particular cognitive skills' behind hominization are not intrinsically related to their increased coupling with a shared exteriorized, non-biological (i.e., technical) memory, as Stiegler shows quite convincingly with Leroi-Gourhan, instead of being rather 'species-specific' (i.e., biological) and only slightly 'contaminated' with technics, as suggested by Vaccari (ibid.).
} 
ways', as Besmer writes, but that it is a phenomenon that is constituted by technology as such and from the very beginning.

As for his critique, insofar as I understand it, that I interpret postphenomenology's invocation of multistability as an argument against technological substantivism (to use Feenberg's notion here) in a merely empirical sense: I cannot deny having conveyed this impression, but the important point I tried to make is that there are decisive systemic and organological limits to the degree of multistability that concrete technical artefacts can offer particular users and that all variations in use and implementation of these artefacts is always constrained by the technical tendency and the processes of concretization followed by technical artefacts independently of user intentions and wants, as Simondon has shown. And industrialization in particular tends to diminish the margins of multistability. As Stiegler quotes Simondon: 'At the industrial level,...the system of wants is less coherent than the system of objects; wants are formed around the industrial technical object, which thereby takes on the power of modeling a civilization' (cited in Stiegler 1998, 73). To be sure, it was not my intention to deny the phenomenon of multistability or technological ambiguity, which clearly resonates with Stiegler's understanding of technology as a pharmakon, only to point out its limited value as a basis for criticizing or dismissing any thinking in terms of 'Technology with a capital T'. Unfortunately I cannot adequately respond to Besmer's comparison of multistability with Merleau-Ponty's notion of 'style' developed in the context of the latter's phenomenology of perception, as I found it hard to grasp the analogy.

Concerning Besmer's impression that my presentation of the transcendental-empirical divide might be exclusionary and that my plea for a rehabilitation of transcendental approaches seems to reject empirical approaches altogether, I can only reply that this is definitely not my intention. The turn to the empirical was and remains a crucial correction to the (allegedly) exclusivist transcendentalism of the so-called classical philosophers of technology, but it turned into an opposite exclusionary exercise itself, to the complete neglect and indeed rejection of transcendental approaches as such, which are the hallmark of any genuinely philosophical approach in my view. Philosophers should always be aware and take into account the transcendental horizons in which their analyses operate or else they remain stuck in what might be called the 'natural attitude', as postphenomenologists are indeed inclined to do, thereby inadvertently adhering to the horizon of understanding Heidegger called Enframing, despite stubbornly rejecting the 'adequacy' of such a transcendental diagnosis (cf. Zwier et al. 2016). Pace Heidegger though I agree with Besmer that the transcendental and the empirical should be 'understood as corollaries, not contraries', and the gist of my article in this regard was precisely to argue for technology as the 'element' that constantly 'mediates' between the two, to use a key concept of postphenomenology in a somewhat different way.

Open Access This article is licensed under a Creative Commons Attribution 4.0 International License, which permits use, sharing, adaptation, distribution and reproduction in any medium or format, as long as you give appropriate credit to the original author(s) and the source, provide a link to the Creative Commons licence, and indicate if changes were made. The images or other third party material in this article are included in the article's Creative Commons licence, unless indicated otherwise in a credit line to the material. If material is not included in the article's Creative Commons licence and your intended use is not permitted by statutory regulation or exceeds the permitted use, you will need to obtain permission directly from the copyright holder. To view a copy of this licence, visit http://creativecommons.org/licenses/by/4.0/. 


\section{References}

Haar, M. (1993). Heidegger and the Essence of Man. Albany: SUNY.

Heidegger, M. (1977). The Question Concerning Technology and Other Essays. New York: Harper \& Row. Heidegger, M. (1984). The Metaphysical Foundations of Logic. Bloomington: Indiana University Press.

Heidegger, M. (1991). Nietzsche. Volumes Three and Four. New York: Harper Collins.

Heidegger, M. (1996). Being and Time. Albany: SUNY.

Heidegger, M. (2001). Einleitung in die Philosophie. Frankfurt am Main: Vittorio Klostermann.

Ihde, D. (1990). Technology and the Lifeworld. From Garden to Earth. Bloomington: Indiana University Press.

Ihde, D. (2016). Husserl's Missing Technologies. New York: Fordham University Press.

Janicaud, D., \& Mattéi, J.-F. (1995). Heidegger. From Metaphysics to Thought. Albany: SUNY.

Lemmens, P. (2017). 'Thinking Through Media. Stieglerian Remarks on a Possible Postphenomenology of Media. Van Den Eede, Y, Irwin O’Neill, S. \& Wellner, G. (ed.). Postphenomenology and Media. Lanham: Lexington Books.

Mules, W. et al. (2009), 'Bernard Stiegler and the Question of Technics', editorial, Transformations. Journal of Media, Culture and Technology, Issue No. 17: http://www.transformationsjournal.org/2009-issueno-17-bernard-stiegler-and-the-question-of-technics/\#

Romele, A. (2020). 'Technological Capital: Bourdieu, Postphenomenology, and the Philosophy of Technology Beyond the Empirical Turn'. Philosophy \& Technology, 23 March 2020.

Schürmann, R. (1990). Heidegger on Being and Acting. From Principles to Anarchy. Bloomington: Indiana University Press.

Smith, D. (2018). Exceptional Technologies. A Continental Philosophy of Technology. London: Bloomsbury.

Stiegler, B. (1998). Technics and Time 1. The Fault of Epimetheus. Stanford: Stanford University Press.

Stiegler, B. (2011). Technics and Time 3. Cinematic Time and the Question of Malaise. Stanford: Stanford University Press.

Stiegler, B. (2013). Pharmacologie du front national. Paris: Flammarion.

Stiegler, B. (2015). Symbolic Misery The Katastrophè of the Sensible. Vol. 2. Cambridge-Malden: Polity.

Vaccari, A. (2009). 'Unweaving the Program. Stiegler and the Hegemony of Technics'. Transformations. Journal of Media, Culture and Technology, Issue No. 17: http://www.transformationsjournal.org/wpcontent/uploads/2017/01/Vaccari_Trans17.pdf

Zwier, J., Blok, V., \& Lemmens, P. (2016). 'Phenomenology and the Empirical Turn: a Phenomenological Analysis of Postphenomenology’. Philosophy \& Technology, 29(4), 313-333.

Pieter Lemmens Pieter Lemmens teaches philosophy and ethics at the Radboud University in Nijmegen, the Netherlands. He has published on themes in the philosophy of technology and new media and on human enhancement technologies, on the work of Martin Heidegger, Peter Sloterdijk and Bernard Stiegler, on the Anthropocene as -well as on post-operaist Marxism (Hardt, Negri, Berardi) and topics related to philosophical anthropology and phenomenology. Current interests include the philosophy of technology in the age of the Anthropocene and the notion of the technosphere. 